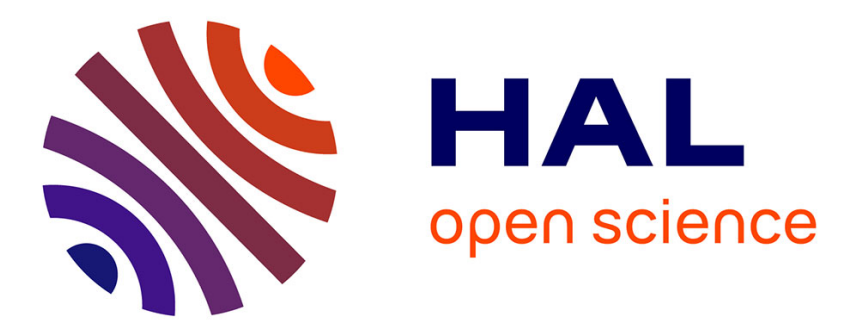

\title{
A Central Control Strategy of Parallel Inverters in AC Microgrid
}

Gang Yao, Yu Lu, Tianhao Tang, Mohamed Benbouzid, Yukai Zheng, Wang Tianzhen

\section{- To cite this version:}

Gang Yao, Yu Lu, Tianhao Tang, Mohamed Benbouzid, Yukai Zheng, et al.. A Central Control Strategy of Parallel Inverters in AC Microgrid. IECON, IEEE, Dec 2013, Vienne, Austria. pp.71127117. hal-01108307

\section{HAL Id: hal-01108307 https://hal.science/hal-01108307}

Submitted on 22 Jan 2015

HAL is a multi-disciplinary open access archive for the deposit and dissemination of scientific research documents, whether they are published or not. The documents may come from teaching and research institutions in France or abroad, or from public or private research centers.
L'archive ouverte pluridisciplinaire HAL, est destinée au dépôt et à la diffusion de documents scientifiques de niveau recherche, publiés ou non, émanant des établissements d'enseignement et de recherche français ou étrangers, des laboratoires publics ou privés. 


\section{A Central Control Strategy of Parallel Inverters in AC Microgrid}

\author{
Gang $\mathrm{Yao}^{1}, \mathrm{Yu} \mathrm{Lu}^{2}$, Tianhao Tang ${ }^{3}$ \\ Electrical Engineering and Automation Department \\ Shanghai Maritime University \\ Shanghai, China \\ 1'gangyao@shmtu.edu.cn, \\ 21uyu9248@163.com, \\ 33thtang@shmtu.edu.cn
}

\author{
Mohamed Benbouzid ${ }^{4}$, Yukai Zheng ${ }^{5}$, Tianzhen Wang ${ }^{6}$ \\ ${ }^{4}$ EA 4325 LBMS, University of Brest, France, \\ Mohamed.Benbouzid@univ-brest.fr \\ ${ }^{5}$ College of Physics Science and Technology, Suzhou \\ University, Suzhou 215006, China \\ ${ }^{6}$ Electrical Engineering and Automation Department \\ Shanghai Maritime University, Shanghai, China
}

\begin{abstract}
This paper focuses on the microgrid control method in different operating modes. The conventional droop control scheme is typically used to achieve autonomous voltage and frequency regulation, which considers only local information, and the global optimal performance can't be guaranteed. In island mode, when the load or generation inside the MG changes, circulations will be generated between the inverters in case the line impedances are mismatch. Furthermore, the MG active power output does not follow the reference in grid connected mode. Dealing with the above problems, a central controller is designed to maintain the stable operation of the microgrid in different modes in this paper. Some simulations are carried out and the results validate the efficiency of the proposed method.
\end{abstract}

Keywords-Microgrid; Distributed generation (DG); Power converters; Droop control; Parallel operation

\section{INTRODUCTION}

Microgrid is a controllable unit that supplies power to consumers on the combination of distributed generations (DGs), energy storage equipment, control devices and loads, which improves the reliability of power supply and represents a new development direction of power system $[1,2]$.

The interfaces between the DG units and MGs are often base on converters, and the final stage of these converters consists of $\mathrm{dc} / \mathrm{ac}$ inverters. When multiple inverters are paralleled in grid connected, synchronization or islanding mode, a droop control scheme is typically adopted, which adjusts the frequency and amplitude of the output voltage, thus active and reactive power can be shared among the inverters [3-4]. But this method still has several drawbacks that limit its application.

Firstly, due to the impedance mismatch between the DG units and the line impedance, the conventional droop control is subject to reactive power coupling. In [5] and [6], the innerloop output impedance of the inverter can be inductive by designing the parameters of the inner controller, But it complicates the controller design. In [7], virtual output

This work was supported by "Shanghai Natural Science Foundation" (11ZR1415100), "Specialized Research Fund for the Doctoral Program of Higher Education" (20113121110002), and "Innovation Program of Shanghai Municipal Education Commission” (11YZ139). impedance loops can solve this problem successfully. In this sense, the output impedance can be seen as a control variable.

Further, in island mode, when the load or generation inside the MG changes, the droop control regulates the output power by changing the amplitude and frequency of voltage [8]. Frequency and voltage deviations are inherent to this method [9]. The power balance causes the deviation of voltage and frequency, and the voltage drop on the line impedance lead to greater deviation [10]. When the line impedance of DG units is mismatch, the output voltage of inverter is not equal, and then the circulation will be generated between the inverters [11]. Moreover, in grid connected mode, the voltage and frequency of PCC can be supported by main grid. Due to the voltage drop on the impedance of line and inverter units, the output active power of the inverter is not a rating, thus it cause the deviation between the output power of inverter and reference value.

To overcome the aforementioned drawbacks, in this paper, a central control strategy is proposed. In island mode, the application of a secondary regulation control loop eliminates voltage deviations, and an active compensator is implemented to eliminate the circulation. In grid connected mode, an external control loop is proposed to regulate the output power of an inverter.

\section{LOCAL CONTROL SYSTEM OF THE DG INVERTER}

Fig. 1 shows the local control structure of a DG inverter. It consists of inner control loop, droop control loop and $P / \mathrm{Q}$ calculations. $v_{o}$ and $i_{o}$ are the output voltage and current of the $\mathrm{DG}$ inverter respectively. The $\mathrm{P} / \mathrm{Q}$ calculator calculates instantaneous values of active and reactive powers; the droop control generates the reference voltage of inner loop; and the inner loop control the output voltage of inverter.

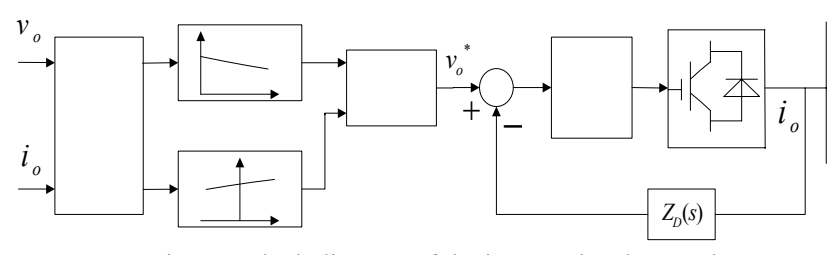

Fig. 1. Block diagram of the inverter local control 


\section{A. Inner Control Loops With The Virtual Output Impedance}

The inner control loop of the three-phase voltage source inverters (VSI) shown in Fig. 2 is designed in $d-q$ reference frame. So Park transformation is used to transform the variables between $a b c$ and $d-q$ frames. In Fig. $2, i_{\mathrm{Ld}} 、 i_{\mathrm{Cd}}$ and $i_{\text {od }}$ are the Inductor current, capacitor current and output current of the inverter respectively. The inner control loop consists of an inner current loop, an external voltage loop and a virtual impedance loop. The proportional integral control used in voltage loop is to maintain the stability of the output voltage. The output of voltage loop as a reference of current loop. In order to control the resonant peak of $L C$ filter and enhance the dynamic response, proportional control be used in current loop

The output impedance of the closed-loop inverter affects the power sharing accuracy. The application of virtual impedance loop can fix the output impedance of the inverter and obtain the desired output impedance.

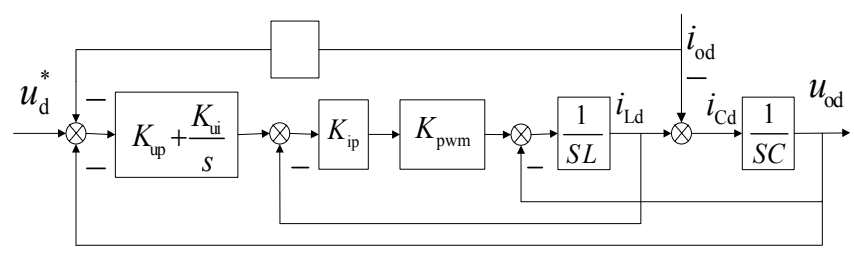

Fig. 2. Block diagram of inner control loop with virtual output impedance

The closed-loop output voltage can be expressed as follows

$$
u_{\text {od }}=G(s) u_{\mathrm{d}}^{*}-Z_{\mathrm{o}}(s) i_{\text {od }}
$$

where $G(\mathrm{~s})$ is the voltage gain and $Z_{\mathrm{o}}(s)$ is the output impedance, $u_{\mathrm{d}}{ }^{*}$ is the output voltage reference. $G(\mathrm{~s})$ and $Z_{\mathrm{o}}(s)$ can be obtained in (2) and (3) as

$$
\begin{aligned}
& G(s)=\frac{k_{u p} k_{i p} k_{p u m} s+k_{u i} k_{i p} k_{p u m}}{L C s^{3}+C k_{i p} k_{p u m} s^{2}+\left(1+k_{u p} k_{i p} k_{p u m}\right) s+k_{u i} k_{i p} k_{p u m}} \\
& Z_{o}(s)=\frac{L s^{2}+\left(1+R k_{u p}\right) k_{u i} k_{p u m} s+R k_{u i} k_{i p} k_{p u m}}{L C s^{3}+C k_{i p} k_{p u m} s^{2}+\left(1+k_{u p} k_{i p} k_{p u m}\right) s+k_{u i} k_{i p} k_{p u m}}
\end{aligned}
$$

where $K_{\text {up }}$ and $K_{\text {ui }}$ are the proportional and integral coefficients of voltage loop, $K_{\mathrm{ip}}$ is the proportional coefficients of current loop, $K_{\mathrm{pwm}}$ is the fundamental wave magnification of inverter, $R$ is the virtual resistive-impedance. $\mathrm{R}^{\mathrm{t}}$ can be observed that adding virtual resistive-impedance which does not affect the stability of the system and just change the output impedance of the inverter.

Using the parameters listed in Table I, the frequency response of Ifterter output impedance is obtained, and illustrated in Fig. 3. It can be seen that the output impedance of the inverter is inductive without virtual resistive impedance. After adding the virtual resistive impedance, the output impedance becomes almost resistive, and the output impedance at line frequency $(50 \mathrm{~Hz})$ is about $0.3 \mathrm{~dB}$ and $0.26^{\circ}$. In this situation, the decoupling between $P$ and $Q$ can be guaranteed.

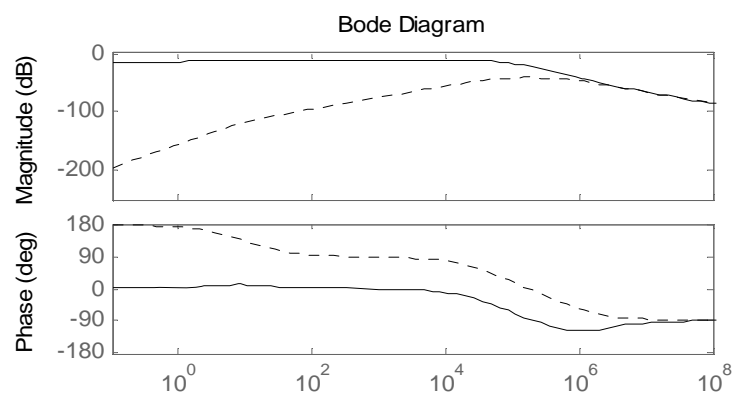

Fig. 3. Bode diagrams of inverter output impedance with (solid line) and without (dashed line) virtual resistive-impedance

\section{B. Droop control system}

Fig. 4 shows the equivalent circuit of two inverters connected to a common load. The output active power and reactive power of inverter can be expressed as follows :

$$
\begin{aligned}
& P_{i}=\left(\frac{E_{i} V}{Z_{i}} \cos \phi_{i}-\frac{V^{2}}{Z_{i}}\right) \cos \theta_{i}+\frac{E_{i} V}{Z_{i}} \sin \phi_{i} \sin \theta_{i} \\
& Q_{i}=\left(\frac{E_{i} V}{Z_{i}} \cos \phi_{i}-\frac{V^{2}}{Z_{i}}\right) \sin \theta_{i}-\frac{E_{i} V}{Z_{i}} \sin \phi_{i} \cos \theta_{i}
\end{aligned}
$$

where $\mathrm{i}=1,2, Z_{i}$ and $\theta_{i}$ are the magnitude and the phase of the output impedance, ${ }_{i}$ is the power angle, $E_{i}$ and $V$ are the amplitude of the inverter output voltage and the common bus voltage.

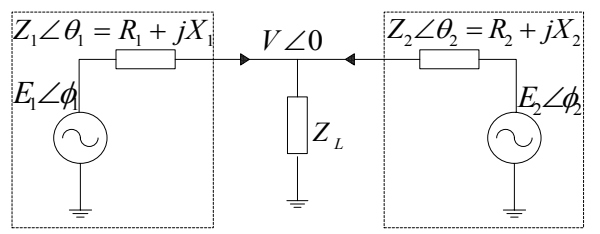

Fig. 4. Equivalent circuit of Parallel operation of two inverters

The output impedance of the inverters and the line impedance are mainly Resistive, and considering small phase difference between $E_{i}$ and $V\left(\cos { }_{i} \approx 1\right.$ and $\left.\sin { }_{i} \approx{ }_{i}\right)$. The equation (4) and (5) can be simplified as

$$
\left\{\begin{array}{c}
E_{i}-E_{i}^{*}=-m\left(P_{i}-P_{i}^{*}\right) \\
f_{i}-f_{i}^{*}=n\left(Q_{i}-Q_{i}^{*}\right)
\end{array}\right.
$$

where $f_{i}$ and $E_{i}$ are the frequency and amplitude of the output voltage reference, $f_{i}^{*}$ and $E_{i}^{*}$ are their references, $P_{i}$ and $Q_{i}$ are the active and reactive power, $P_{i}^{*}$ and $Q_{i}{ }^{*}$ are their references, and $m$ and $n$ are the droop frequency and amplitude coefficients. Itean be seen that actiy power $P$ is regulated by the inverter output voltage amplitude $E$, while reactive power $Q$ can be controlled by the inverter output voltage frequency, which is the opposite strategy to the conventional droop method. follows

The droop coefficient ( $m$ and $n$ ) can be designed as

$$
\begin{aligned}
& m=\Delta V / P_{\max } \\
& n=\Delta f / 2 Q_{\text {max }}
\end{aligned}
$$

where $P_{\max }$ and $Q_{\max }$ are the maximum active and reactive 
power of the inverter output, $\Delta V$ and $\Delta f$ are the maximum frequency and voltage allowed of the inverters. The value of droop coefficient relates to the system synchronized and the voltage stability limits.

\section{IMPROVED CONTROL SYSTEM DESIGN}

The MG can operate in island, grid connected and switching mode. Using local controller, the global optimal performance can't be guaranteed. The central controller should be designed to maintain the stable operation of the MG in different modes.

\section{A. Control Strategy in Island Mode}

In island operation, the inverter operates as a voltage source. When the line impedance of the inverters is mismatch, the output voltage amplitude of the inverters is not equal. It affects the active power sharing of DG units and produces circulation between the inverters. Further droop control regulates the output power by changing the amplitude and frequency of voltage, when the load or generation inside the MG changes. The inherent trade off of droop control between frequency amplitude regulation and active, reactive power sharing accuracy cannot be avoided. The stability of the voltage at the PCC affects the quality of power supply and seamless switch the microgrid between the different operating modes.

In order to restore the deviation of the PCC voltage and eliminate the circulation between the inverters, the corresponding controller is proposed. It is implemented as expressed in

$$
\left\{\begin{array}{c}
E_{i}=E_{i}^{*}-m\left(P_{i}-P_{i}^{*}\right)+\Delta E_{1}+\Delta E_{2} \\
f_{i}=f_{i}^{*}+n\left(Q_{i}-Q_{i}^{*}\right)+\Delta f
\end{array}\right.
$$

where $\Delta E_{1}$ and $\Delta f$ are the deviations, that can be obtained in $(8)$ and (9) as

$$
\begin{aligned}
& \Delta E_{1}=\left(K_{\mathrm{pE}}+\frac{K_{\mathrm{iE}}}{s}\right)\left(E_{\mathrm{PCC}}^{*}-E_{\mathrm{PCC}}\right) \\
& \Delta f=\left(K_{p f}+\frac{K_{i f}}{s}\right)\left(f_{\mathrm{PCC}}^{*}-f_{\mathrm{PCC}}\right)
\end{aligned}
$$

where $f_{\mathrm{PCC}}, E_{\mathrm{PCC}}$ are the frequency and amplitude of voltage at PCC, $f_{\mathrm{PCC}}{ }^{*}$ and $E_{\mathrm{PCC}}{ }^{*}$ are their reference respectively, $K_{\mathrm{pE}}, K_{\mathrm{iE}}$, $K_{\mathrm{pf}}$, and $K_{\mathrm{if}}$ are the control parameters of PI regulation. The frequency and amplitude of the $\mathrm{MG}, f_{\mathrm{PCC}}$ and $E_{\mathrm{PCC}}$, are measured then compared with the references $f_{\mathrm{PCC}}{ }^{*}$ and $E_{\mathrm{PCC}}{ }^{*}$. After PI regulation, the deviations are sent to all the DG units to restore the output-voltage frequency and amplitude.

Take the $P-V$ droop as an example, and analysis the control principle. In Fig. 5, the intersection $a$ of the power curve $P_{\mathrm{G}}$ and the load curve $P_{\mathrm{L}}$ is a nominal operating point of the MG. The load curve changes to $P_{\mathrm{L} 1}$, as the load increasing, then the MG operates in the point $b$. It can be seen that there is a deviation between the voltage amplitude and the rating. The application of secondary regulation leads to the translation of power curve. When the power curve is $P_{\mathrm{L} 1}$, the MG operates in the point $c$, and the voltage of the $\mathrm{MG}$ is equal to the rating.

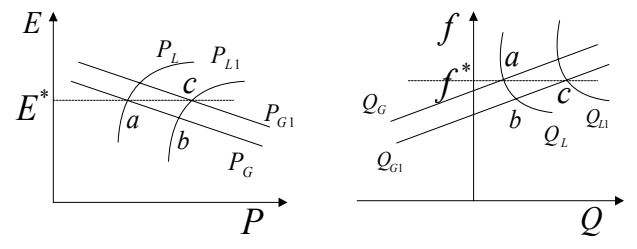

Fig. 5. the diagram of the voltage deviations restore

$\Delta E_{2}$ is the active compensation value, that can be obtained in (10) and (11) as

$$
\begin{gathered}
\Delta E_{2}=\left(K_{p c}+\frac{K_{i c}}{s}\right)\left(\bar{P}_{i}-P_{i}\right) \\
\bar{P}_{i}=P_{\text {total }} / n
\end{gathered}
$$

where $P_{i}$ is output active of the inverters, $P_{\text {total }}$ is the active output by all the inverters, $n$ is the number of inverters, $\bar{P}_{i}$ is the active power demand of the inverters, $K_{\mathrm{pc}}$, and $K_{\mathrm{ic}}$ are the control parameters of PI regulation. Through calculation the sum of active power output to obtain active power references of the inverters [11]. The central controller regulates the active power of each inverter via PI controllers.

\section{B. Synchronization Control Strategy}

In order to smoothly switch the MG between the islanding mode and the connection mode, it is required to implement the synchronous control loop. In synchronization mode, the frequency and voltage of the $\mathrm{MG}$ and main grid should be measured, and the $\theta_{m}, \mathrm{E}_{m}$ can be compared with the $\theta_{g}$ and $\mathrm{E}_{g}$, the control laws can be expressed as in the following

$$
\left\{\begin{array}{c}
E_{i}=E_{i}^{*}-m\left(P_{i}-P_{i}^{*}\right)+\Delta E_{t} \\
f_{i}=f_{i}^{*}+n\left(Q_{i}-Q_{i}^{*}\right)+\Delta f_{t}
\end{array}\right.
$$

where $\Delta E_{\mathrm{t}}$ and $\Delta f_{\mathrm{t}}$ can be obtained in (14) and (15) as

$$
\begin{gathered}
E_{\text {ref }}=E^{*}+\left(k_{p 1}+\frac{k_{i 1}}{s}\right)\left(E_{g}-E_{m}\right) \\
f_{\text {ref }}=f^{*}+\left(k_{p 2}+\frac{k_{i 2}}{s}\right)\left(\theta_{g}-\theta_{m}\right)
\end{gathered}
$$

where $\theta_{\mathrm{g}}, \mathrm{E}_{\mathrm{g}}$ are the phase-angle and amplitude of main grid voltage, $\theta_{\mathrm{m}}, \mathrm{E}_{\mathrm{m}}$ are the phase-angle and amplitude of $\mathrm{MG}$ voltage, $k_{\mathrm{p} 1}, k_{\mathrm{i} 1}, k_{\mathrm{p} 2}$, and $k_{\mathrm{i} 2}$ are the control parameters of the synchronous control loop. After several cycles, the synchronization process will finish, and then the MG can be connected to the mains grid through the static bypass switch. Operation mode of $\mathrm{MG}$ from islanding to grid connected. Then the synchronous control loop quit operation.

\section{C. control strategy in grid connected mode}

After synchronization procedure, it is allowed that connect the microgrid to the main grid. In grid connected mode, the amplitude and frequency of the $\mathrm{MG}$ voltage depend on the main grid. Supposing the frequency of main grid remain power frequency $(50 \mathrm{HZ})$ and the voltage of main grid stay the same, equaling to the nominal voltage of inverter. From (10), it can be seen that the output reactive power of inverter is the rated power. Due to the voltage drop on the impedance of line and inverter units, which produce deviations between the 
output voltage of the inverter units and the nominal voltage. The output active power of the inverter is not a rating.

An advanced control strategy is proposed to improve this weakness. The block diagram of control law is presented in Fig. 6, and it can be expressed as in the following

$$
E_{i}=E_{i}^{*}-m\left(P_{i}-P_{i}^{*}\right)+\left(k_{p P}+\frac{k_{i P}}{s}\right)\left(P_{r e f}-P_{i}\right)
$$

where $P_{i}$ and $P_{\text {ref }}$ are the output active power of inverter and its reference. $K_{\mathrm{pP}}$ and $K_{i \mathrm{P}}$ are the control parameters of active power control loop. By measuring the active output power of the inverter, $P$ can be compared with the $P_{\text {ref, after PI }}$ controller, the deviations are sent to the droop control loop to regulate amplitude reference of the inverter. The output active voltage can be controlled by this means. When the microgrid operates in the grid connecting mode, the constant power control can be achieved.

According to the control strategy proposed above, the control scheme is shown in Fig. 6.

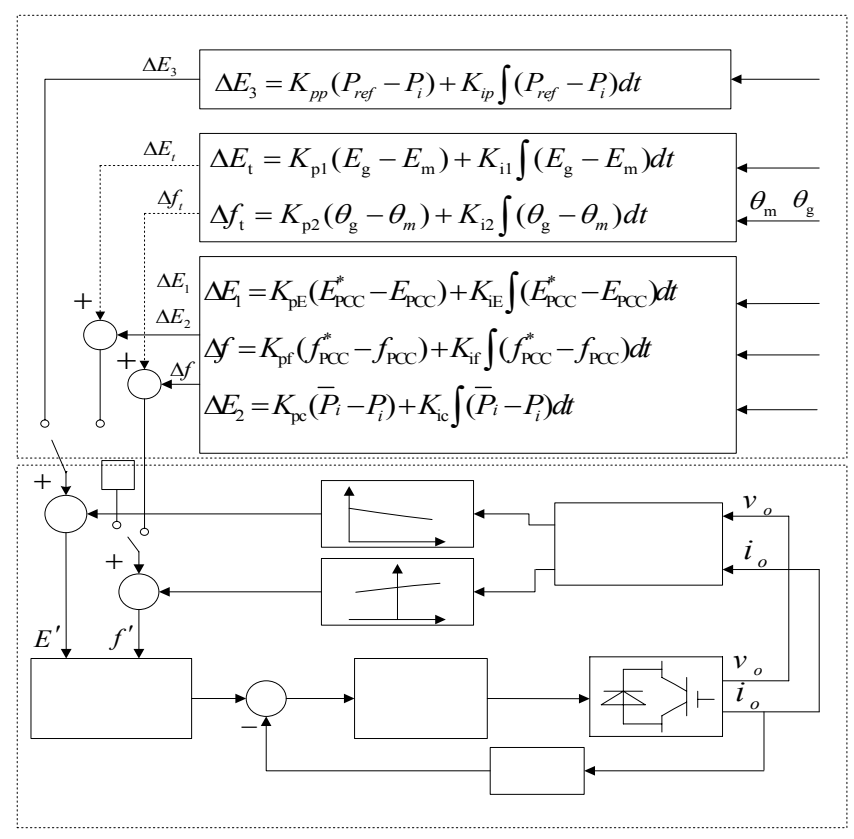

Fig. 6. Block diagram of the proposed control scheme

\section{Simulation Results}

In this paper, a microgrid model has been established Gsientral con MATLAB/Simulink to verify the feasibility of the control method. As shown in Fig. 7, the microgrid includes of two parallel inverter and load. The two inverters (DG1, DG2) parallel operate sharing the load. The inverters consist of a Three-phase full-bridge with an $L C$ filter. The controller consists of the voltage and current control loop with virtual impedance, the droop control loop, the $P / \mathrm{Q}$ calculator and the central controller. The power stage and controller parameters are listed in Table I and Table II. Switching frequency of the DGs inverters is set to $6 \mathrm{kHz}$. The inverter active and reactive power reference value are $5 \mathrm{~kW}$ and $0 \mathrm{kVar}$ respectively. The DC link voltage: $V_{\mathrm{dcl}}=650 \mathrm{~V}, V_{\mathrm{dc} 2}=600 \mathrm{~V}$. The line impedance of the two inverters: $Z_{1}=0.64+\mathrm{j} 0.0083, Z_{2}=0.34+\mathrm{j} 0.0083$.

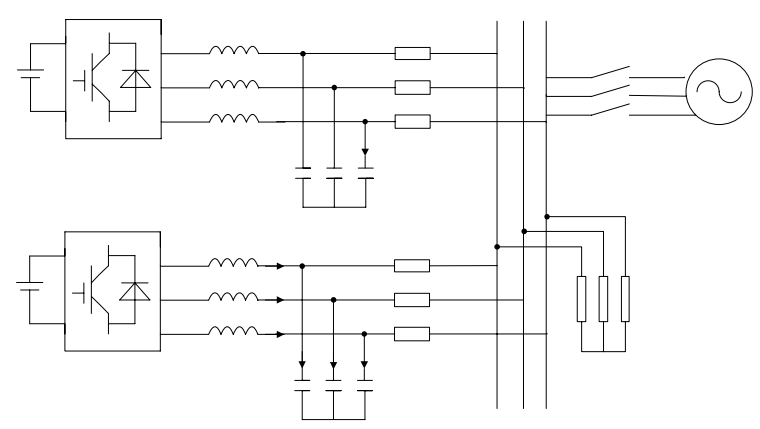

Fig. 7. The structure of microgrid in the simulation.

Table I. Power stage and inner controller parameters

\begin{tabular}{|c|c|c|c|}
\hline Parameter & Symbol & Value & Units \\
\hline Grid voltage & $\mathrm{V}$ & 311 & $\mathrm{~V}$ \\
Grid frequency & $f$ & 50 & $\mathrm{~Hz}$ \\
rated output power(DG1/2) & $\mathrm{S}$ & 5 & $\mathrm{KVA}$ \\
Inverter inductance & $\mathrm{L} 1, \mathrm{~L} 2$ & 2 & $\mathrm{mH}$ \\
Inverter capacitance & $\mathrm{C} 1, \mathrm{C} 2$ & 200 & $\mu \mathrm{F}$ \\
Amplitude droop coefficient & $\mathrm{m}$ & 0.001 & $\mathrm{Ws} / \mathrm{V}$ \\
Frequency droop coefficient & $\mathrm{n}$ & 0.0005 & $\mathrm{Var} / \mathrm{rd}$ \\
voltage proportional term & $K_{\mathrm{up}}$ & 10 & $\mathrm{~V}^{-1}$ \\
voltage Integral term & $K_{\mathrm{ui}}$ & 100 & $\mathrm{~S} / \mathrm{V}$ \\
current proportional term & $K_{\mathrm{ip}}$ & 4 & $\mathrm{~A}^{-1}$ \\
resistive virtual impedance & $R$ & 0.2 & $\Omega$ \\
\hline
\end{tabular}

Table II. The central controller parameters

\begin{tabular}{|c|c|c|l|}
\hline Parameter & Symbol & Value & Units \\
\hline Amplitude proportional term & $K_{\mathrm{pE}}$, & 0.17 & W/V \\
Amplitude integral term & $K_{\mathrm{iE}}$, & 27 & Ws $/ \mathrm{V}$ \\
Frequency proportional term & $K_{\mathrm{pf}}$ & 0.3 & Vars $/$ rd \\
Frequency integral term & $K_{\mathrm{if}}$ & 15 & Var/rd \\
Active amplitude proportional term & $K_{\mathrm{pc}}$ & 0.0068 & W/V \\
Active amplitude integral term & $K_{\mathrm{ic}}$ & 0.1 & Ws $/ \mathrm{V}$ \\
Active proportional term & $K_{\mathrm{pP}}$ & 0.0015 & W/V \\
Active integral term & $K_{\mathrm{iP}}$ & 0.01 & Ws $/ \mathrm{V}$ \\
\hline
\end{tabular}

\section{A. islanding operating}

First, the microgrid operates in islanding mode and two inverter share the $5 \mathrm{~kW}$ load. At $0.6 \mathrm{~s}$, the load changes from $5 \mathrm{~kW}$ to $9 \mathrm{~kW}, 2 \mathrm{kVar}$. At $0.12 \mathrm{~s}$, the load decreases to $7 \mathrm{~kW}$, $1 \mathrm{kVar}$. The result is shown in Fig. 8 and Fig. 9.

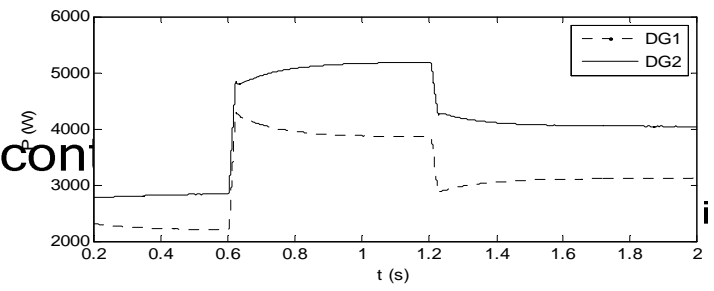

(a) Active power delivered by DG1 and DG2

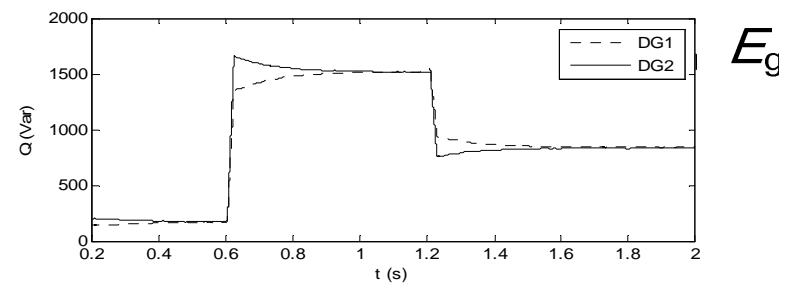

(b) Reactive power delivered by DG1 and DG2 $E_{\text {pcc }}$ 


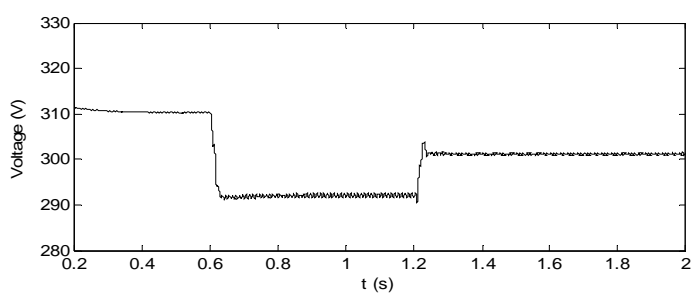

(c) Microgrid voltage

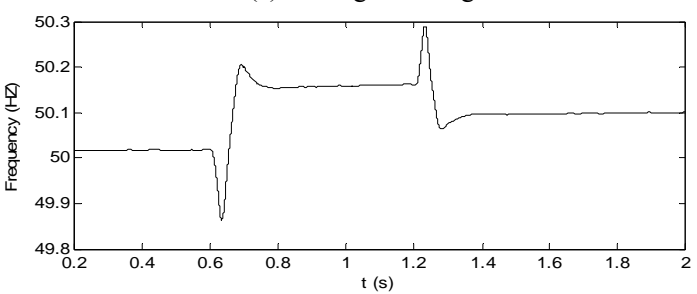

(d) Microgrid frequency

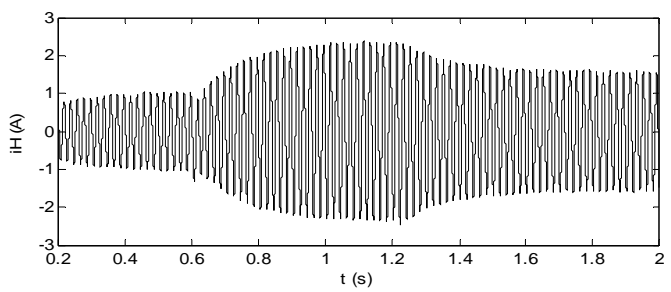

(e) The circulation between the two inverters

Fig. 8. The result of the microgrid without the central controller.

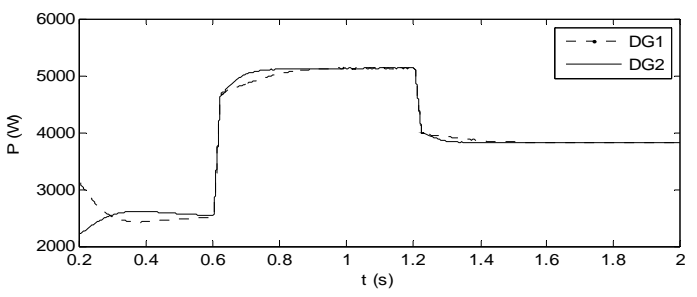

(a) Active power delivered by DG1 and DG2

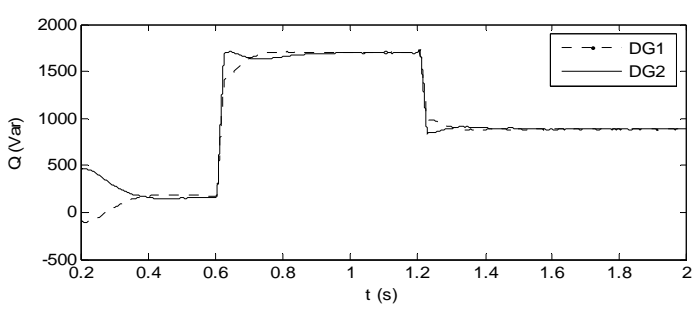

(b) Reactive power delivered by DG1 and DG2

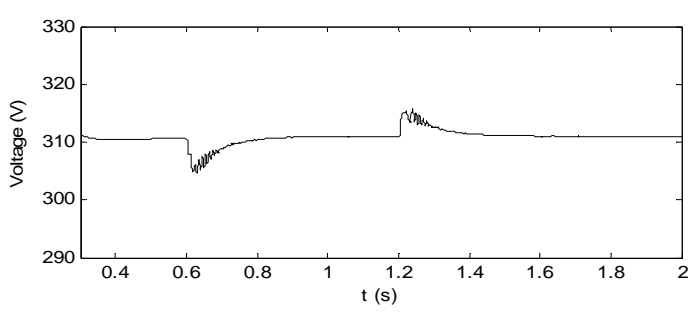

(c) Microgrid voltage

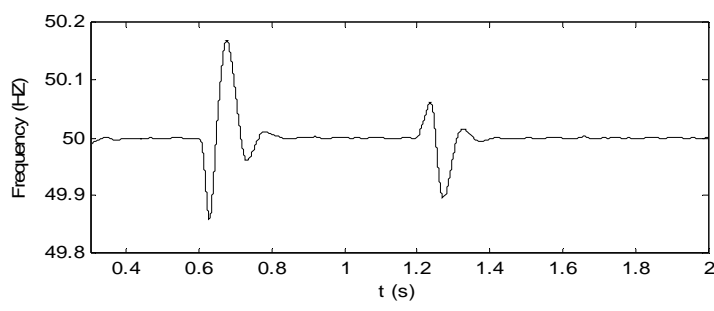

(d) Microgrid frequency

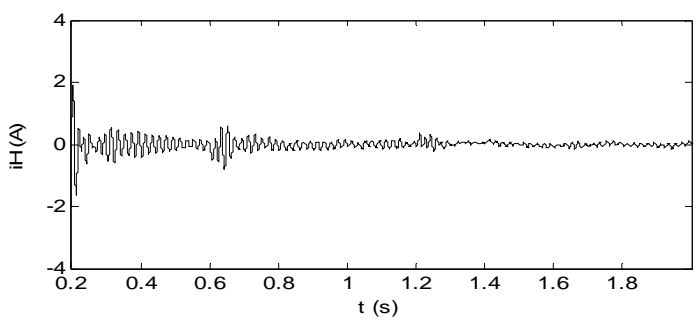

(e) The circulation between the two inverters

Fig. 9. The result of the microgrid with the central controller

Fig.8 and Fig.9 show the active and reactive power delivered by DG1 and DG2, the transient response of the frequency and amplitude of the $\mathrm{MG}$ and the circulation between the two inverters for load changes. It can be seen from the result that the increase of output power of inverters leads to the decrease of the voltage amplitude and the increase of the frequency, which conform to the $P-V, Q-f$ control characteristic. From the Fig. 8 (a) and (e), the active power output of two DGs is not equal; the mismatch of the line impedance can produce the circulation between the two inverters. From the Fig.8(c) and (d), the load changes, the frequency and amplitude of voltage have deviations.

Fig. 9 shows the result of the $\mathrm{MG}$ with the central controller. From the Fig. 8 (a) and (e), the active power output of two DGs is equal and the circulation between two inverters is reduced. From the Fig.8 (c) and (d), the application of the central controller can quickly respond to the changes, the voltage frequency and amplitude deviations are regulated toward zero after every change of load. The control strategy enhanced the power quality of the MG.

\section{B. Islanding To Grid Connected}

First, the MG is in islanded mode, two inverter share the 5 $\mathrm{kW}$ load. At $0.5 \mathrm{~s}$ synchronization control works to prepare for connecting to the main grid. After the synchronization process, at $1.3 \mathrm{~s}$ the $\mathrm{MG}$ is connected to the main grid. The simulation result is showed in Fig.10, Fig. 11 and Fig.12.

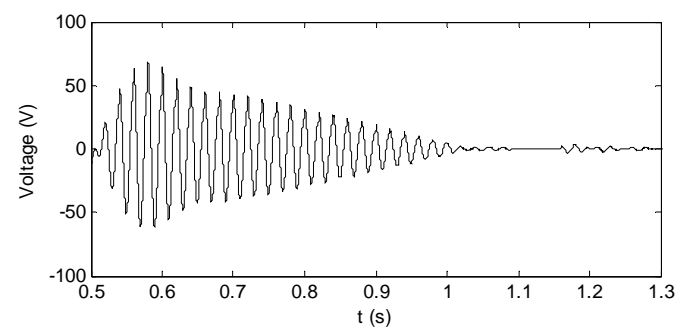

Fig. 10. Voltage difference between the main grid and the MG during the synchronization process. 


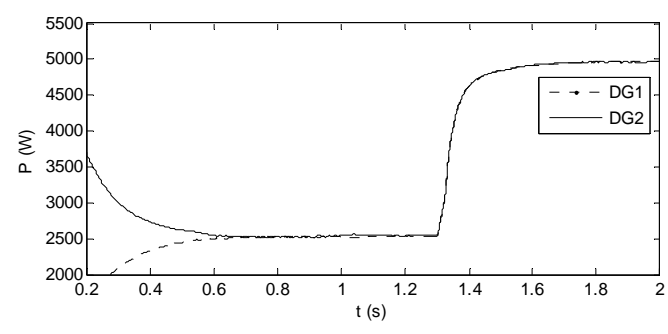

(a) Active power delivered by DG1 and DG2

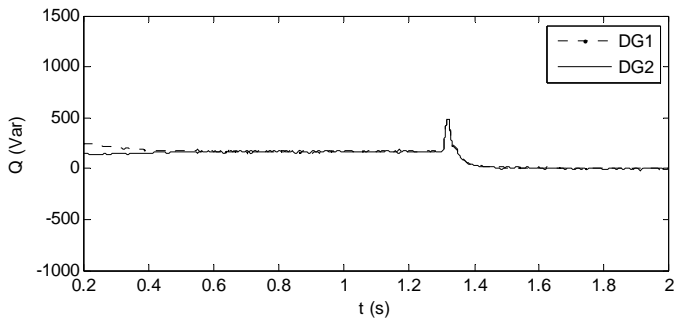

(b) Reactive power delivered by DG1 and DG2

Fig. 11. Power transient response from islanded to grid-connected mode

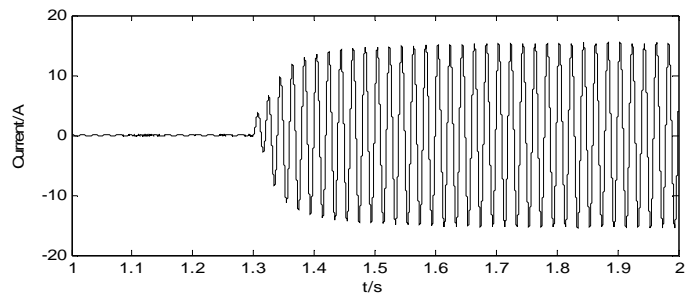

(a) Currents waveform at the PCC

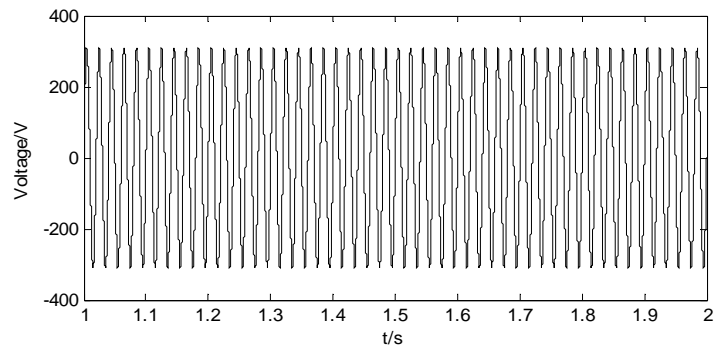

(b) Voltage waveform at the PCC

Fig. 12. Transient response of the output currents and voltage of PCC

Fig. 10 shows the voltage difference between the MG and the main grid during the synchronization process. It can be seen that the error difference between them is decreasing. $t>$ $1.1 \mathrm{~s}$, the voltage error difference approaches zero.

Fig. 11 shows the power transient response of inverters. $0 \mathrm{~s}<\mathrm{t}<1.3 \mathrm{~s}$, the MG in islanding mode, two DGs share the 5 $\mathrm{kW}$ load equally. At $\mathrm{t}=1.3 \mathrm{~s}$, the $\mathrm{MG}$ connects to the main grid, the power output of inverter follows the power reference value. The output power $\mathrm{P}_{1,2}=5 \mathrm{~kW}, \mathrm{Q}_{1,2}=0 \mathrm{kVar}$. The result shows that the control strategies perform successfully during island and grid connected modes and the transitions modes.

Fig. 12 (a) shows the Currents waveform at the $\mathrm{PCC}, 0 \mathrm{~s}<\mathrm{t}$ $<1.3 \mathrm{~s}, \mathrm{MG}$ in islanding mode, the current at the $\mathrm{PCC}$ is zero. $\mathrm{t}$
$>1.3 \mathrm{~s}, \mathrm{MG}$ in grid connected mode, the power inject to the main grid. The current total harmonic distortion (THD) value of is $\mathrm{THD}=0.45 \%$, fundamental current $=14.18 \mathrm{~A}$. THD $<0.5 \%$, it meet the requirements of connection to main grid [12]. Fig. 12 (a) shows the Voltage waveform at the PCC, The THD value of is $\mathrm{THD}=0.01 \%$, fundamental Voltage $=311.1 \mathrm{~V}$. The result shows that the Seamless switching from islanding to grid connected can be achieved.

\section{CONCLUSION}

In this paper, a central control strategy was proposed by analyzing the operation characteristics of the MG. According to the different operation mode of the MG, the corresponding control method is proposed. In island mode, the implement of secondary regulation loop eliminated voltage deviations of PCC, and enhanced the power quality of the MG. The application of active compensator eliminated the circulation between two inverters. In grid connected mode, the output power of inverter followed the rating using an active power control loop. In addition, the application of synchronous control strategy enhanced seamless switching microgrid between islanding and grid connected mode. The simulation results showed the high reliability and flexibility of the microgrid during different operation mode.

\section{REFERENCES}

[1] Lu Zongxiang,Wang Caixia,Min Yong,et al.Overview on microgrid research [J]. Automation of Electric Power Systems, 2007,31(19):100107.

[2] Sheng Kun,Kong Li,Qi Zhiping,et al.A survey on research of microgrid-a new power system[J].Relay, 2007, 35(12):75-81.

[3] Rocabert J, Luna A, Blaabjerg F, etal. Control of Power Converters in AC Microgrids[J]. IEEE TRANSACTIONS ON POWER ELECTRONICS, 2012, 27(11):4734-4749.

[4] Guerrero J M, Hang L, Uceda J. Control of Distributed Uninterruptible Power Supply Systems[J]. IEEE TRANSACTIONS ON INDUSTRIAL ELECTRONICS, 2008, 55(8):2845-2859.

[5] Wang Chengshan, Gao Fei, Li Peng, et al. Control Strategy Research on Low Voltage Microgrid [J]. Proceedings of the CSEE, 2012, 32(25):2-8.

[6] Xiao Zhaoxia, Wang Chengshan, Wang Shouxiang. Multiple feedback loop control scheme for inverters of the micro source in microgrids $[\mathrm{J}]$. Transactions of China Electrotechnical Society,2009,24(2):100-107.

[7] Guerrero J M, José Matas, Luis García de Vicuña, et al. Decentralized Control for Parallel Operation of Distributed Generation Inverters Using Resistive Output Impedance[J]. IEEE TRANSACTIONS ON INDUSTRIAL ELECTRONICS, 2007, 54(2):994-1004.

[8] Yang Xiangzhen, Su Jianhui, Ding Ming, et al. Voltage Control Strategies for Microgrid With Multiple Inverters [J]. Proceedings of the CSEE, 2012, 32(7):7-13.

[9] Guerrero J M, Vasquez J C, Matas J, etal. Hierarchical control of droopcontrolled AC and DC microgrids: a general approach toward standardization[J]. IEEE Transactions on Industrial Electronics, 2011, 58(1):158-172.

[10] Savaghebi M, Jalilian A, Vasquez J C, etal. Secondary Control Scheme for Voltage Unbalance Compensation in an Islanded Droop-Controlled Microgrid[J]. IEEE TRANSACTIONS ON SMART GRID, 2012, 3(2):797-807.

[11] A. Micallef, M. Apap, C. Spiteri-Staines, J. M. Guerrero "Secondary Control for Reactive Power Sharing in Droop-Controlled Islanded MicroGrids" IEEE ISIE, 2012.

[12] Yang Zhichun, Le Jian, Liu Kaipei, etal. Study on the standard of the grid-connected microgrids[J]. Power System Protection and Control, 2012, 40(2): 66-71. 